\title{
Optimal Synthesis and Implementation of Resonant Vibratory Systems
}

\author{
Volodymyr Gursky*, Igor Kuzio, Vitaliy Korendiy \\ Department of Mechanics and Automation Engineering (MAE), Lviv Polytechnic National University, Ukraine
}

Copyright $\subseteq 2018$ by authors, all rights reserved. Authors agree that this article remains permanently open access under the terms of the Creative Commons Attribution License 4.0 International License

\begin{abstract}
The problems of synthesis and substantiation of elasticity parameters of the resonant vibratory device with electromagnetic drive and one flat spring are considered. At first, the harmonic systems with oscillation frequencies of $50 \mathrm{~Hz}$ and $100 \mathrm{~Hz}$ were investigated. Then, various asymmetric piecewise linear characteristics of elasticity were carried into effect on one flat spring using auxiliary intermediary fixed cylindrical supports. Due to this, the corresponding vibro-impact operation modes were obtained. The resonant systems characterized by improved functioning efficiency were carried into effect using the new technique of optimization synthesis of elasticity parameters. The resonant systems being investigated were implemented in practice. The basic experimental investigations of their kinematic, dynamic and energetic parameters were carried out. The fundamental result of the investigation consists in confirmation of the improved dynamic efficiency of vibro-impact systems with pulsed electromagnetic excitation designed according to the new technique. The proposed systems may be used in technological processes of materials compaction and screening, of surface treatment of machine parts and in processes associated with nanotechnology.
\end{abstract}

Keywords Vibro-impact, Electromagnetic Drive, Resonance, Synthesis, Piecewise Linear Characteristics

\section{Introduction}

Vibratory systems and machines are useful for various technological purposes [1] and are commonly used as multiform technical means. The field of application of vibratory machines covers new progressive methods of surface and bulk treatment of materials. The implementation of multi-frequency oscillations ensures the use of vibratory technological systems in the fields of nanotechnology and in problematic energy-intensive industries. However, the development of effective systems requires the search for new designs and calculation methods in order to use energy-efficient resonant modes [2]. For this purpose, it is expedient to use advanced methods of dynamic analysis, synthesis and optimization of parameters [3] with simultaneous ensuring of the specified technological factors.

\section{Methodology of Synthesis and Optimization}

The research is aimed at a generalized analysis and synthesis of resonant two-mass systems with harmonic and vibro-impact modes. The first stage of the research was the selection of criteria (indexes, parameters) that form a complex of requirements to the class of resonant systems. Taking into account the structure of the mechanical system, the vibratory machines may have a different number of oscillating masses. As a rule, only one of these masses is considered as technological one. Therefore, in terms of technological expediency, in order to evaluate the system, it is enough to use the maximum value of acceleration only of the working mass $a_{1 \max }$ (or g-force $\Gamma=a_{1 \max } / g$ ) and consumed (intake) power $P$. In this case, the target energy criterion has the following form:

$$
\varsigma_{1} \equiv \varsigma_{a}=a_{1 \max } / P \Rightarrow \max .
$$

The index defines the energy efficiency of the operation in order to attain the key kinematic parameter.

The criterion of $\varsigma_{2}$ is the efficiency factor, which defines the degree of losses of electromechanical oscillatory system $\eta_{1}$ or technological system $\eta_{2}$ (if one takes into account the technological process)

$$
\varsigma_{2} \equiv \eta_{1} \vee \eta_{2} .
$$

The criterion of $\varsigma_{3}$ defines the occurrence of the vibro-impact mode by the value of the coefficient of acceleration asymmetry $k_{a}$ of the working mass (for single-frequency systems $k_{a} \cong 1$ )

$$
\varsigma_{3} \equiv k_{a}=a_{1 \max }\left|a_{1 \min }\right| \text {. }
$$


The criterion of $\varsigma_{4}$ is the width of the resonance zone, which evaluates the technological stability of the vibratory system

$$
\varsigma_{4} \equiv \omega_{0}-\omega .
$$

It is expedient to implement the vibro-impact systems using the asymmetric piecewise linear elastic characteristics. The value of the natural frequency (self-frequency) of oscillations for the system with asymmetric piecewise linear elastic characteristic $\omega_{0}$ without the gap is the function of inertia and stiffness parameters [4]:

$$
\omega_{0}=2 \omega_{0 I} \omega_{0 I I} /\left(\omega_{0 I}+\omega_{0 I I}\right) .
$$

where the corresponding natural frequencies of oscillations corresponds to the directions of action of corresponding stiffness coefficients of the springs. Herewith, the coefficients $c_{1}$ and $c_{2}$, which are in rather wide limits, remain unknown and may be presented as follows:

$$
c_{1}=\omega_{0 I}^{2} \cdot m_{1} m_{2} /\left(m_{1}+m_{2}\right), \quad c_{2}=\omega_{0 I I}^{2} \cdot m_{1} m_{2} /\left(m_{1}+m_{2}\right) .
$$

In order to simplify the synthesis procedure, it is proposed to determine the actual values of the natural frequencies of oscillations by the relationships:

$$
\omega_{0 I}=\Theta \omega / z, \omega_{0 I I}=\Lambda \omega_{0 I},
$$

here $z=\omega / \omega_{0}$ is setting of the resonance; frequency coefficient $\Theta$ and natural frequencies ratio $\Lambda$ are the syntheses parameters.

Synthesis is carried out in accordance with the kinematic characteristics of the vibro-impact mode and ensuring the predefined value of the natural frequency of oscillations (the width of the resonance zone) within the appropriate limits. For example:

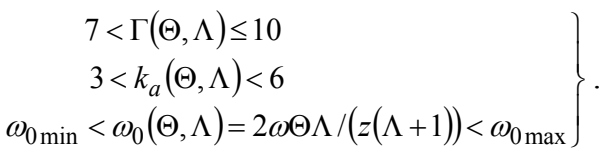

The conditions in Eq. (8) are specified taking into account the technological purpose of the vibratory system.

It is expedient to implement the synthesis problem using the optimization condition according to the power criterion:

$$
\varsigma_{a}(\Theta, \Lambda) \rightarrow \max .
$$

The proposed method of calculation allows to reduce $\Theta<1$ and to increase $\Theta>1$ of the stiffness coefficient of the elastic element being calculated stiffness coefficient of the string, unlike for the traditional method $\Theta=1$. By specifying the value of the natural frequency $\omega_{0}(\Theta, \Lambda) \geq 2 \omega$ in the condition of Eq. (8), the vibro-impact modes are implemented on the subharmonic under the impulse excitation of the system. The proposed methodology is based on the generalized mathematical model of the dynamic system of the vibratory device.

\section{Methodology of Development, Calculation and Modeling}

The structure of the vibratory device (see Fig. 1) used for carrying out the theoretical and experimental investigations is designed according to the two-mass scheme. The structure consists of the body $1\left(m_{1}=22 \mathrm{~kg}\right)$ and reactive 2 ( $m_{2}=11 \mathrm{~kg}$ ) oscillating masses, which are attached by the flat spring 3 . The intermediary fixed cylindrical supports 5 are attached to the body mass 1 with a help of the side plates 4 . For power disturbance of oscillating masses, the electromagnetic drive of alternating current is used. The cores 6 of electromagnets are fastened on the body mass 1 , and the armatures 7 are fixed on the reactive mass 2 . The structure also includes the rubber vibration isolators and the profile frame. The circuit for switching on the electromagnets may be pulsed (for $50 \mathrm{~Hz}$ ) or reactive (for $100 \mathrm{~Hz}$ ).
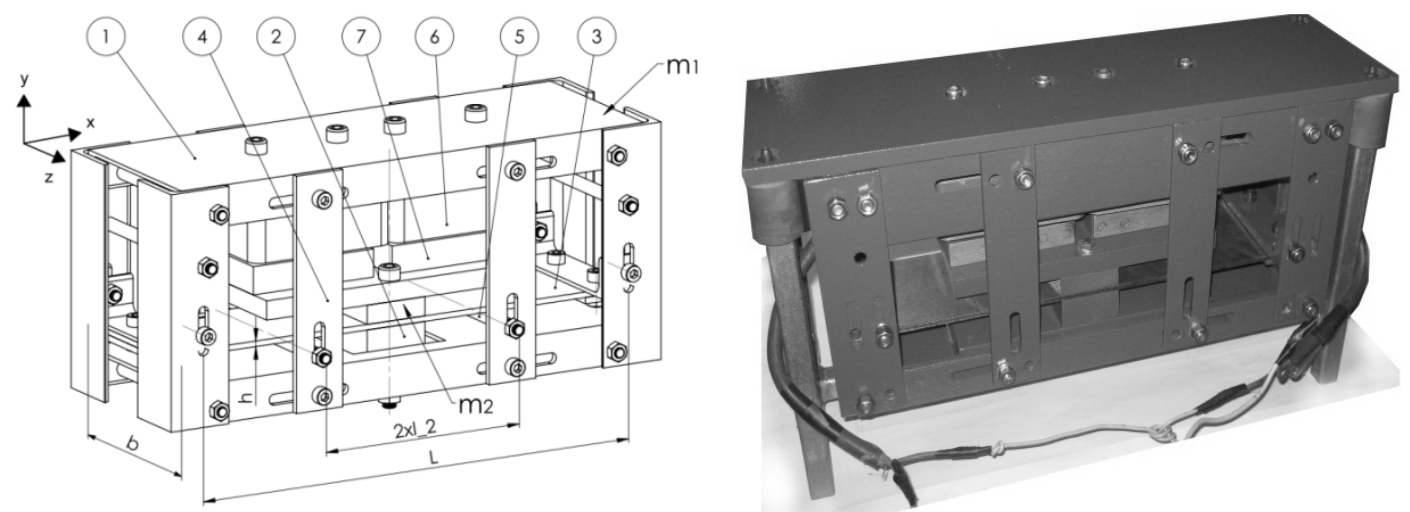

Figure 1. A general view of the two-mass resonant vibratory device: 1 - working mass; 2 - reactive mass; 3 - flat spring; 4 - side plate; 5 - cylindrical supports; 6,7-core and armature of electromagnets 
The use of cylindrical supports 5 with the possibility of regulation of their position allows obtaining linear and piecewise linear elastic characteristics (see Fig. 2) in order to implement harmonic and vibro-impact modes.
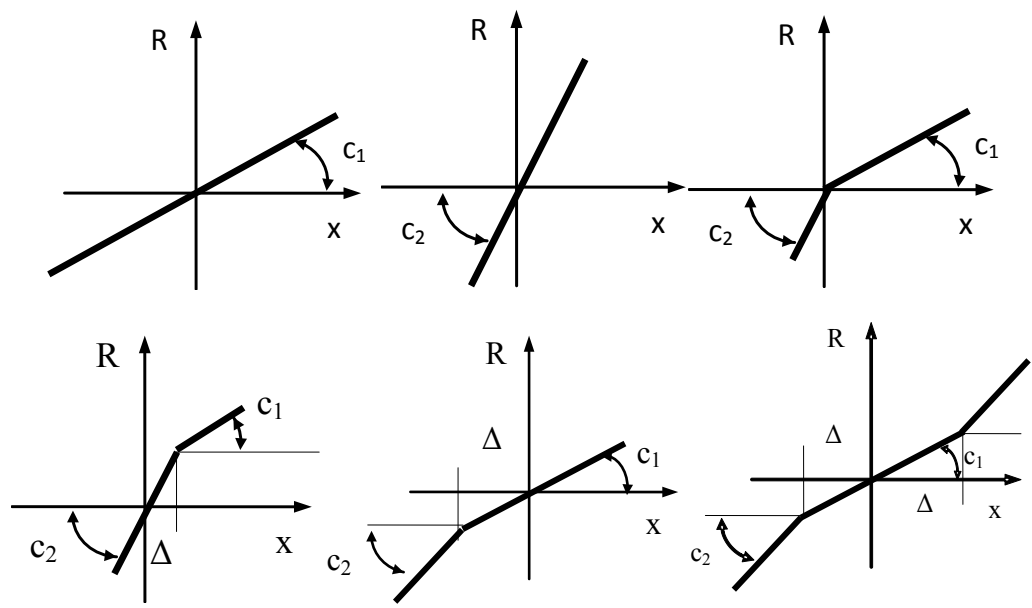

Figure 2. Possible elastic characteristics of the vibratory device

The diagram of implementation of asymmetric piecewise linear elastic characteristic (see Fig. 3) allowed to obtain basic calculation formulas with a help of the finite element method [5]. In order to ensure the first natural frequency one may use the formula, which corresponds to the fastening diagram I of the flat spring:

$$
E J=\frac{m_{w} L^{3} \omega_{0 I}^{2}}{192},
$$

where $m_{w}=m_{1} m_{2} /\left(m_{1}+m_{2}\right)$.

The value of the second natural frequency depends on the position of the cylindrical supports and may be determined by the following formula for the fastening diagram II:

$$
\omega_{0 I I}=4 \cdot \sqrt{\frac{6 E J \cdot\left(2 \cdot L-3 \cdot l_{1}\right)}{m_{w} \cdot L \cdot\left(L-2 \cdot l_{1}\right)^{3}}} .
$$

If we take into account the vertical stiffness of the intermediary supports in the form of the coefficient $c_{\mathrm{y}}$, the corresponding value of the natural frequency of oscillations for the diagram II will be as follows:

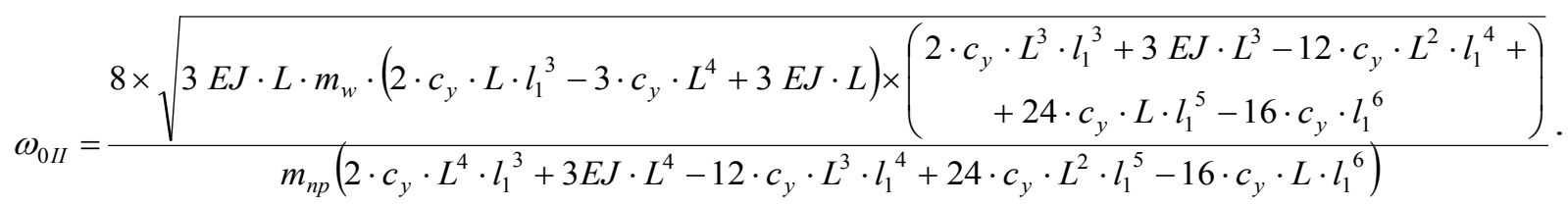

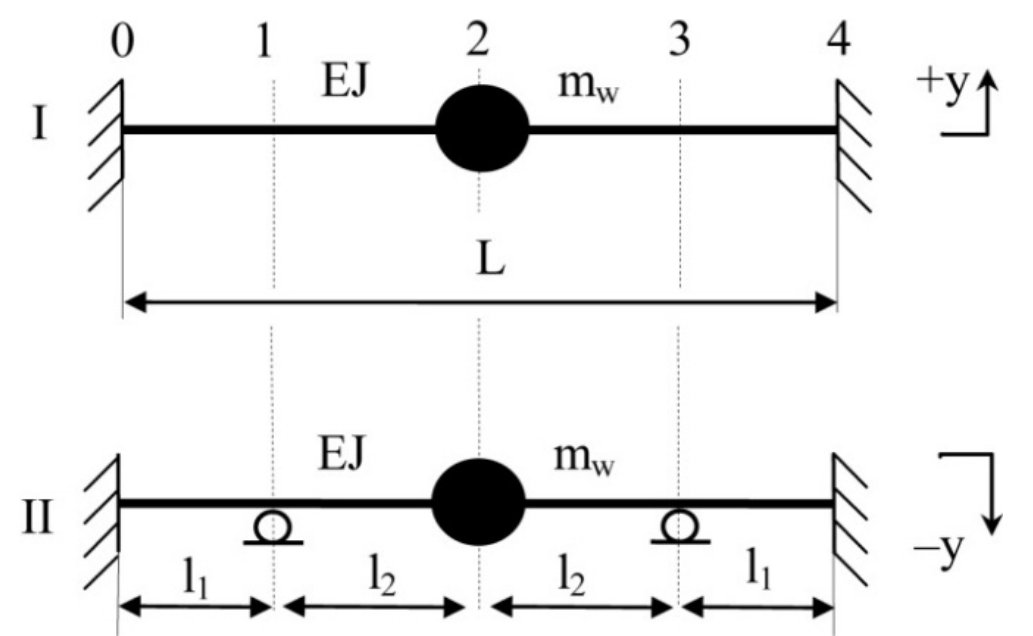

Figure 3. Diagrams of implementation of asymmetric piecewise linear elastic characteristic on one flat spring 
The mathematical model that describes the dynamic processes in the oscillatory system with power electromagnetic excitation is as follows $[6,7]$ :

$$
\begin{aligned}
& \frac{\mu_{0} S w^{2}}{2\left(\delta_{0}-\left(y_{1}(t)-y_{2}(t)\right)\right)} i(t)+\left[r+\left\{\begin{array}{l}
r^{<+>}, \text {if } i(t) \geq 0 \\
r^{<->}, \text {if } i(t)<0
\end{array}+\frac{\mu_{0} S w^{2}\left(\dot{y}_{1}(t)-\dot{y}_{2}(t)\right)}{2\left(\delta_{0}-\left(x_{1}(t)-x_{2}(t)\right)\right)^{2}}\right] i(t)=U_{0} \sin (\omega t) ;\right. \\
& m_{1} \ddot{y}_{1}(t)+\left\{\begin{array}{l}
c_{1}\left(y_{1}(t)-y_{2}(t)\right)+b_{1}\left(\dot{y}_{1}(t)-\dot{y}_{2}(t)\right), \\
\text { if } y_{1}(t)-y_{2}(t) \geq 0 \\
c_{2}\left(y_{1}(t)-x_{2}(t)\right)+b_{2}\left(\dot{y}_{1}(t)-\dot{y}_{2}(t)\right), \\
\text { if } y_{1}(t)-y_{2}(t)<0
\end{array} \quad=\frac{\mu_{0} S w^{2} n}{4}\left[\frac{i(t)}{\delta_{0}-\left(y_{1}(t)-y_{2}(t)\right)}\right]^{2} ;\right. \\
& m_{2} \ddot{y}_{2}(t)-\left\{\begin{array}{l}
c_{1}\left(y_{1}(t)-y_{2}(t)\right)+b_{1}\left(\dot{y}_{1}(t)-\dot{y}_{2}(t)\right), \\
\text { if } y_{1}(t)-y_{2}(t) \geq 0 \\
c_{2}\left(y_{1}(t)-x_{2}(t)\right)+b_{2}\left(\dot{y}_{1}(t)-\dot{y}_{2}(t)\right), \\
\text { if } y_{1}(t)-y_{2}(t)<0
\end{array} \quad=-\frac{\mu_{0} S w^{2} n}{4}\left[\frac{i(t)}{\delta_{0}-\left(y_{1}(t)-y_{2}(t)\right)}\right]^{2} .\right.
\end{aligned}
$$

Parameter designations of the electromagnetic system: coefficients of viscous friction $b_{1}=\gamma c_{1} / \omega$ and $b_{2}=\gamma c_{2} / \omega$; coefficient of internal non-elastic strength (resistance) of the springs material $\gamma=0.04$; magnetic penetration of air $\mu_{0}=4 \pi \cdot 10^{-7}$ henry $/ \mathrm{m}$; number of coil turns $w=800$; surface area of magnet poles $S=2.25 \cdot 10^{-3} \mathrm{~m}^{2}$; active coil resistance $r=18 \Omega ;$ diode resistance in direct $r^{<+>}=0.1 \Omega$ and reverse $r^{<->}=1.33 \cdot 10^{5} \Omega$ directions; nominal value of air gap in electromagnets $\delta_{0}=0.004 \mathrm{~m}$; the number of electromagnets performed at the same time (in parallels) $n=2$; setting of the resonance $z=0.95$; disturbance frequency $\omega=314 \mathrm{~s}^{-1}$; nominal value of voltage $U_{0}$.

The most widespread and the simplest exciting circuits of the vibratory devices are the pulse $50 \mathrm{~Hz}$ one and the reactive $100 \mathrm{~Hz}$ one (see Fig. 4). In the first circuit, the diode and the thyristor rectifiers are used. In the second circuit, the power supply of the electromagnets is carried out directly from the network. However, the new frequency-controlled circuits are currently more prospective [6].

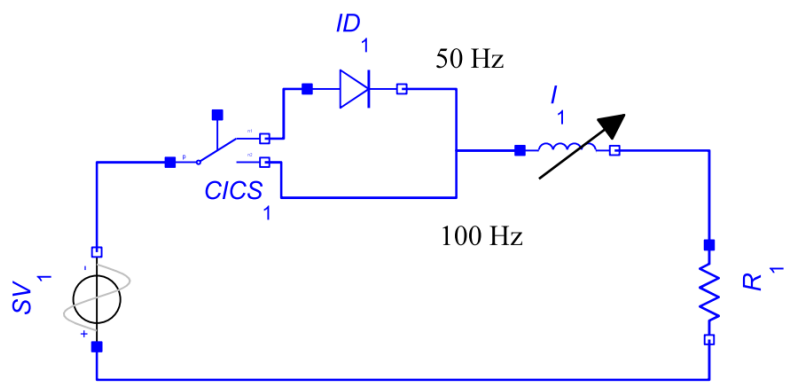

Figure 4. Circuit of power supply of the alternating current electromagnet for exciting the oscillations of the frequencies of $50 \mathrm{~Hz}$ and $100 \mathrm{~Hz}$

The modelling of the system of ordinary nonlinear differential equations (see Eq. (12)) is carried out using the progressive numerical methods, in particular, Radau, BDF, AdamsBDF. The time dependencies of the all kinematics' and power parameters being defined: the g-force of oscillating mass $m_{1}$ is shown (see Fig. 5 and Fig. 6).

The main results of calculation using the methodology of optimization synthesis are presented in Table 1. The highest efficiency of operation is characteristic of vibro-impact system with the synthesis coefficients $\Theta=0.75, \Lambda=2$.

\begin{tabular}{|c|c|c|c|c|c|}
\hline System & $\mathrm{f},[\mathrm{Hz}]$ & $\mathrm{f}_{0},[\mathrm{~Hz}]$ & $\Gamma$ & $\begin{array}{l}\mathrm{U}_{0}, \\
{[\mathrm{~V}]}\end{array}$ & $\begin{array}{c}\mathrm{S}_{\mathrm{a}}, \\
{\left[\left(\mathrm{m} / \mathrm{s}^{2}\right)\right.} \\
\mathrm{W}]\end{array}$ \\
\hline $\begin{array}{c}\text { vibro-impact } \\
\text { without gap } \\
\Theta=1, \Lambda=2\end{array}$ & 50 & 70.2 & \multirow{4}{*}{10} & 204 & 0.23 \\
\hline $\begin{array}{c}\text { vibro-impact } \\
\text { without gap } \\
\begin{array}{c}\Theta=0.75 \\
\Lambda=2\end{array}\end{array}$ & 50 & 52.6 & & 93 & 1.13 \\
\hline \multirow{2}{*}{$\begin{array}{l}\text { single-frequen } \\
\text { cy } \Theta=\Lambda=1\end{array}$} & 50 & 52.6 & & 136 & 0.5 \\
\hline & 100 & 105.3 & & 227 & 0.2 \\
\hline
\end{tabular}

Table 1. Theoretical modes and performance indexes of the vibratory device

The coefficients $\Theta$ and $\Lambda$ are to be calculated using the basic parameters of the vibratory device. In particular, we know the inertial parameters of the device $m_{1}=22 \mathrm{~kg}$, $m_{2}=11 \mathrm{~kg}$ and the necessary frequency of oscillations $\omega=314.15 \mathrm{rad} / \mathrm{s}$. The coefficients of stiffness ensure the near-resonance operation mode with the setting factor $z=0.95$ and can be calculated using the formulas (see Eq. (6) and Eq. (7)) and the synthesized coefficients $\Theta=0.75$ and $\Lambda=2$. The values of the coefficients are as follows: $c_{1}=4.511 \cdot 10^{5} \mathrm{~N} / \mathrm{m}, c_{2}=1.804 \cdot 10^{6} \mathrm{~N} / \mathrm{m}$. The ratio of the coefficients equals $c_{2} / c_{1}=\Lambda^{2}=4$. The resultant value of the natural frequency of oscillations calculated using the formula (see Eq. (5)) is as follows $\omega_{0}=330.694 \mathrm{rad} / \mathrm{s}$. The coefficients of viscous friction 
are also determined: $b_{1}=57.436 \mathrm{Ns} / \mathrm{m}, b_{1}=229.745 \mathrm{Ns} / \mathrm{m}$. At the next stages, the simulation of the system's operation and the selection of the appropriate value of the voltage $U_{0}$ should be carried out in order to ensure the necessary overload on the working mass.

For introducing the system into practice, the bending stiffness of the flat spring is to be calculated using (see Eq. (10)) and the following values of parameters: $m_{w}=7.33 \mathrm{~kg}, L=0.35 \mathrm{~m}$ and $\omega_{0 I}=248.02 \mathrm{rad} / \mathrm{s}$.

The value of stiffness equals $E J=100.735 \mathrm{~N} \cdot \mathrm{m}^{2}$. At the next stage, the distance between the intermediate cylindrical supports is calculated using the (see Eq. (11)): $l_{1}=0.079 \mathrm{~m}$.

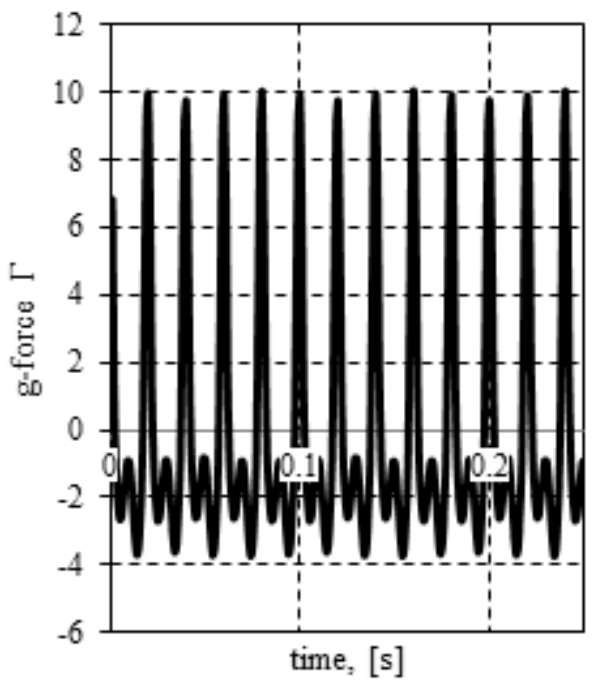

(a)

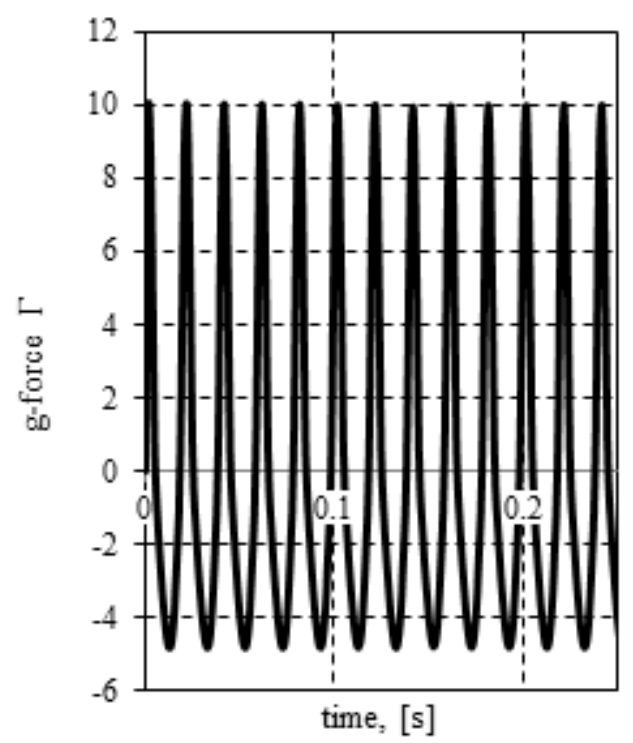

(b)

Figure 5. G-force characteristics of the vibro-impact systems: a) $-\Theta=$ 1 and $\Lambda=1 ; b)-\Theta=0.75$ and $\Lambda=2$

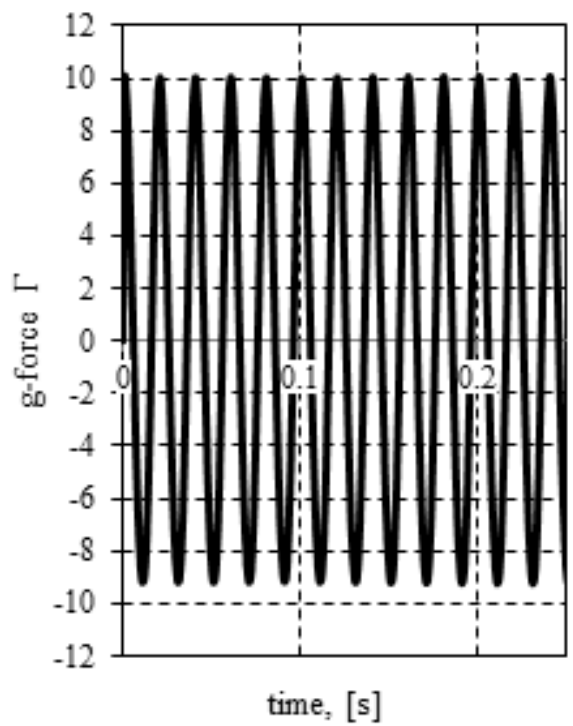

(a)

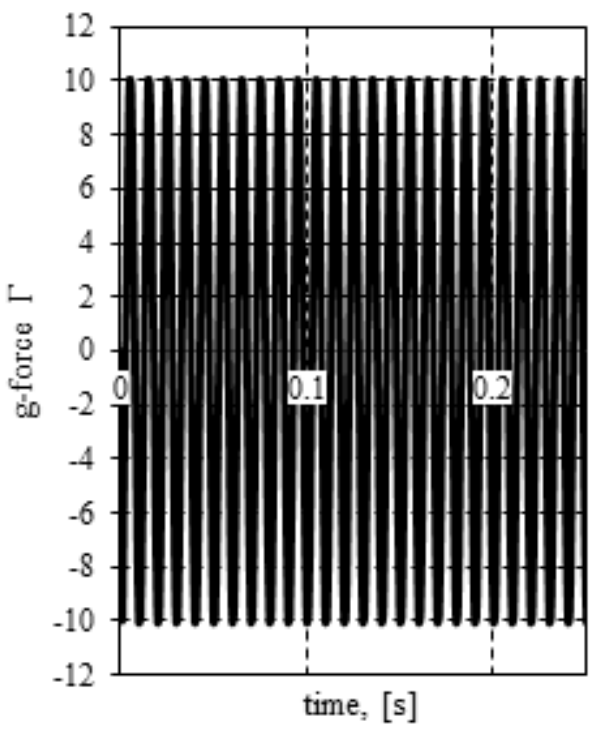

(b)

Figure 6. G-force characteristics of the harmonic systems: a) $-50 \mathrm{~Hz}$ system; b) - $100 \mathrm{~Hz}$ system

\section{Experimental Investigation of the Resonant Vibratory Systems}

\subsection{Investigation of the Single-frequency Resonant Vibratory Systems}

Experimental investigations were carried out using a two-channel USB-oscillograph with two accelerometers $(66[\mathrm{mV}] / \mathrm{g}$ and $200[\mathrm{mV}] \mathrm{g})$, frequency generator, digital frequency meter, ammeter and laboratory autotransformer. 
The implementation and investigation of single-frequency vibratory systems with traditionally calculated elastic parameters were the problems of the first priority. Obviously, for such systems, the coefficients of synthesis are equal $\Theta=\Lambda=1$. The single-frequency systems with $50 \mathrm{~Hz}$ (see Fig. 7) and $100 \mathrm{~Hz}$ (see Fig. 8) modes were implemented and investigated.

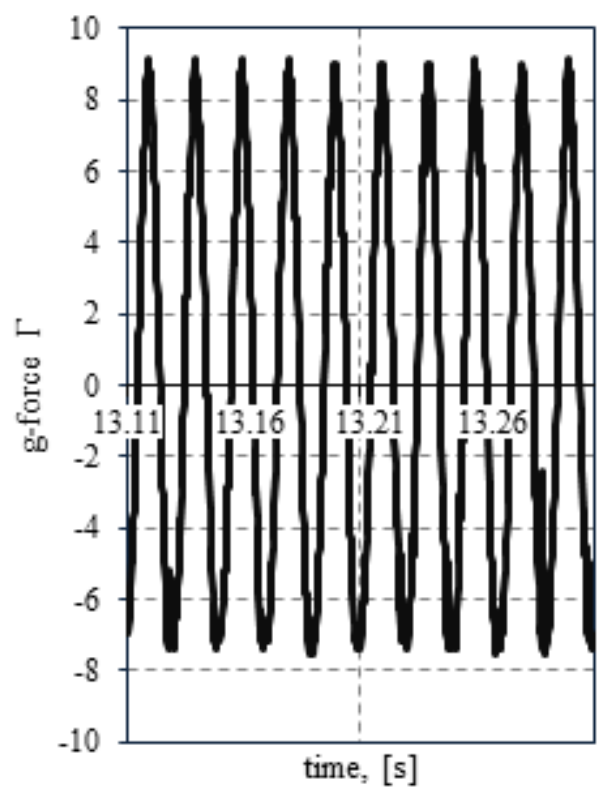

(a)

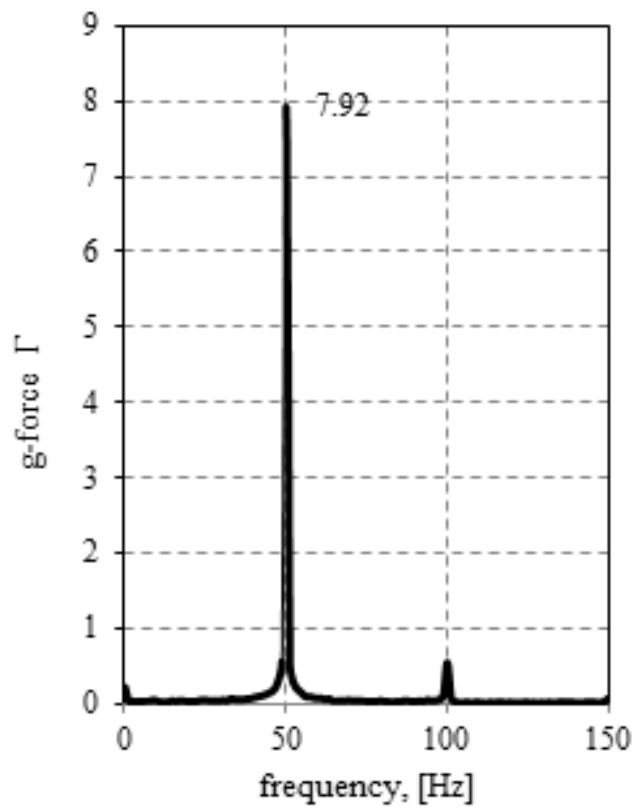

(b)

Figure 7. Kinematic characteristics of the harmonic $50 \mathrm{~Hz}$ system when $U_{0}=165 \mathrm{~V}:$ a) - oscillogram; b) - spectrums of g-force of the body mass

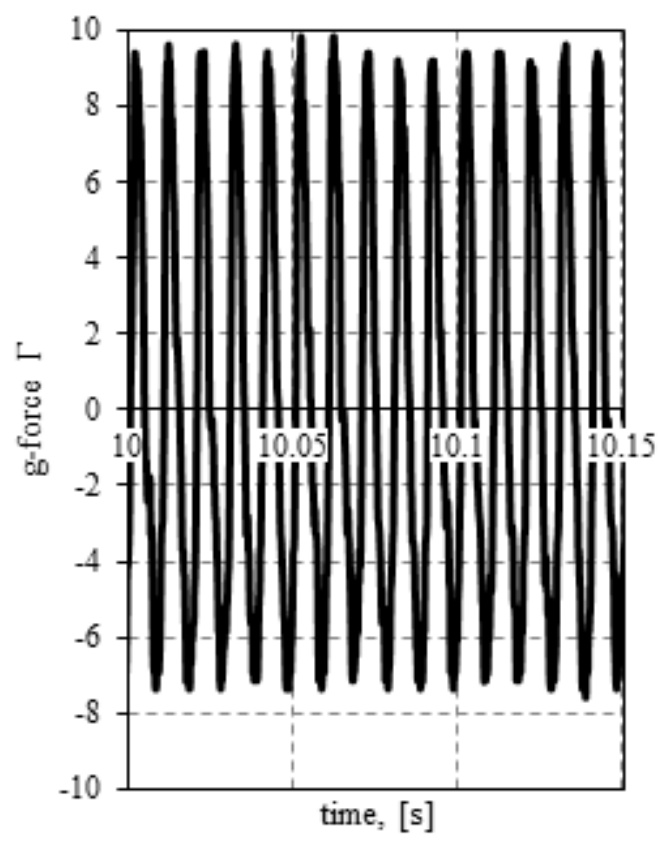

(a)

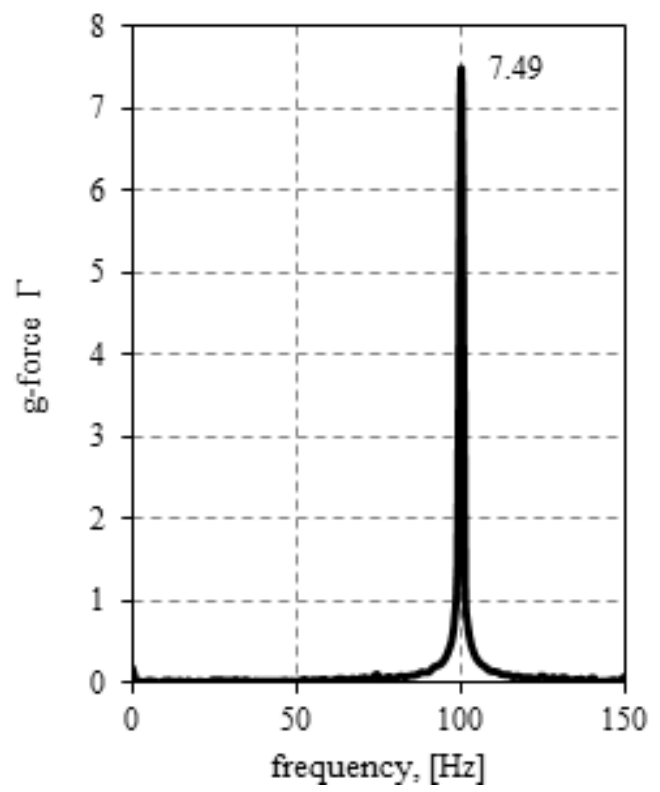

(b)

Figure 8. Characteristics of overloads of the body mass for $100 \mathrm{~Hz}$ harmonic mode when $U_{0}=205 \mathrm{~V}$ : a) - oscillogram, b) - spectral analysis

As a rule, the single-frequency systems with linear elastic characteristics have one harmonic. This fact is confirmed by the spectral analysis being carried out (see Fig. 8, b).

\subsection{Investigation of the Vibro-impact Resonant Vibratory Systems}

Due to the use of intermediary supports, the vibro-impact systems with the oscillations frequencies of $50 \mathrm{~Hz}$ and $100 \mathrm{~Hz}$ were implemented. For these systems, 
the synthesis parameters have the following values: $\Theta=1$, and $\Lambda$ depends on the distance between the supports $\Lambda=1.8 \ldots 2.7$. The characteristic of $50 \mathrm{~Hz}$ vibro-impact mode for the parameter $\Lambda=2$ is presented in Fig. 9 and the characteristic of the vibro-impact system with the excitation frequency of $100 \mathrm{~Hz}$ when $\Lambda=2.2$ is presented in Fig. 10. Using the values of the corresponding coefficients, one may determine the natural frequency of oscillations by the formulas of Eq. (5) and Eq. (7).

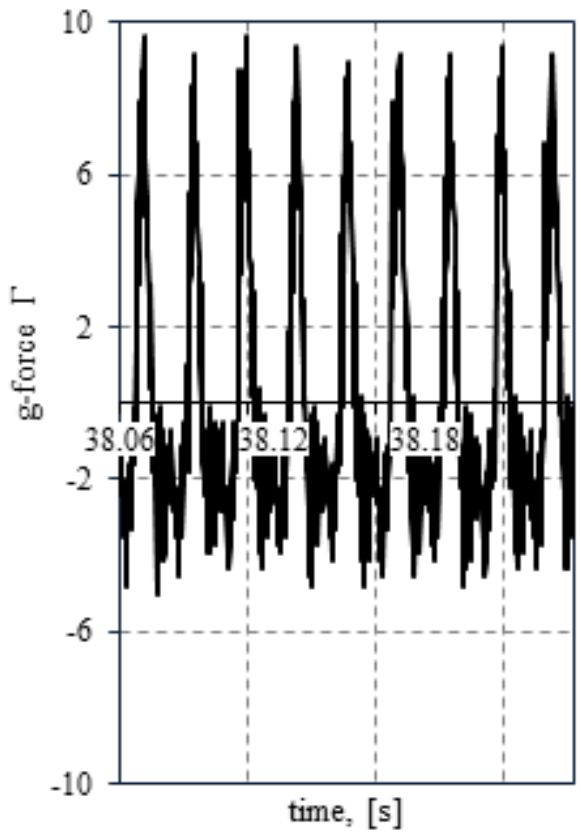

(a)

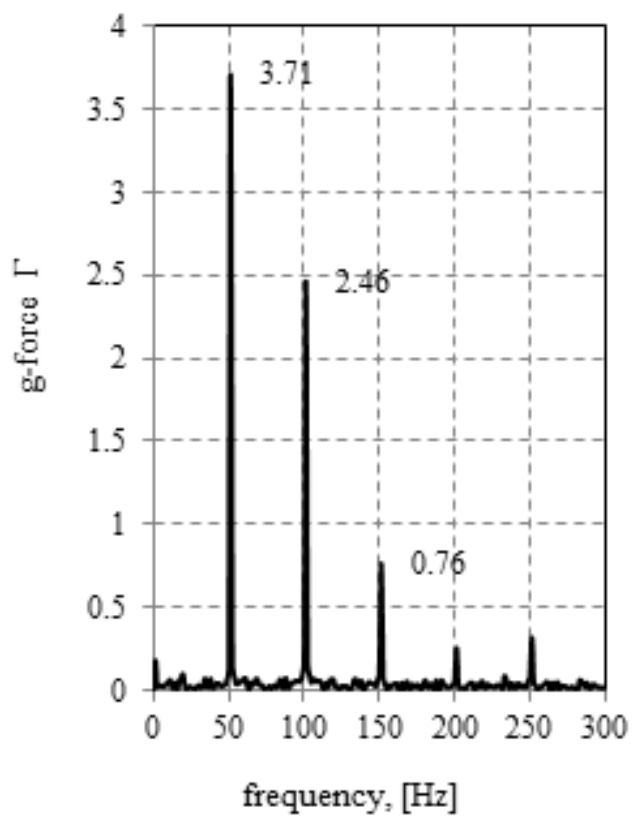

(b)

Figure 9. Kinematic characteristics of the vibro-impact $50 \mathrm{~Hz}$ system when $U_{0}=220 \mathrm{~V}$ : a) - oscillogram of overloads; b) - spectrums of overloads of the body mass

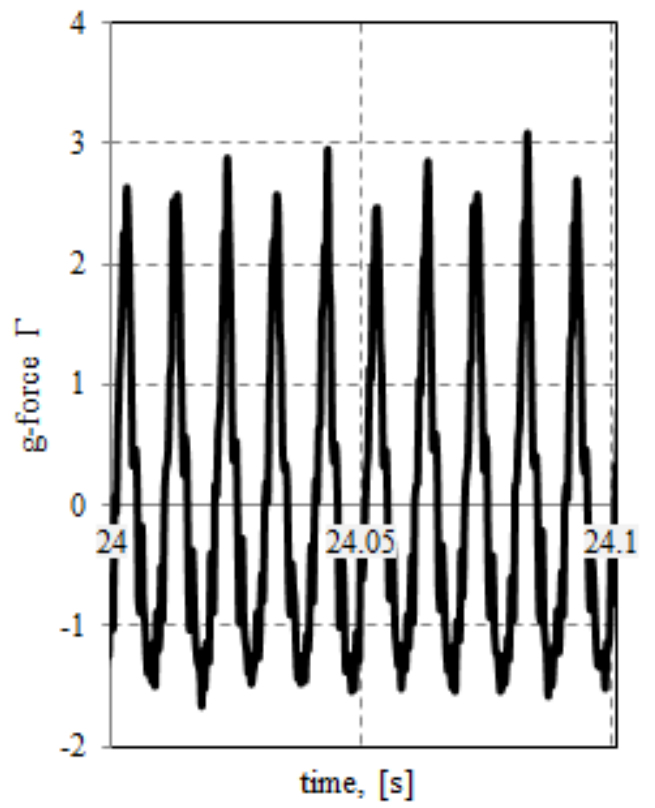

(a)

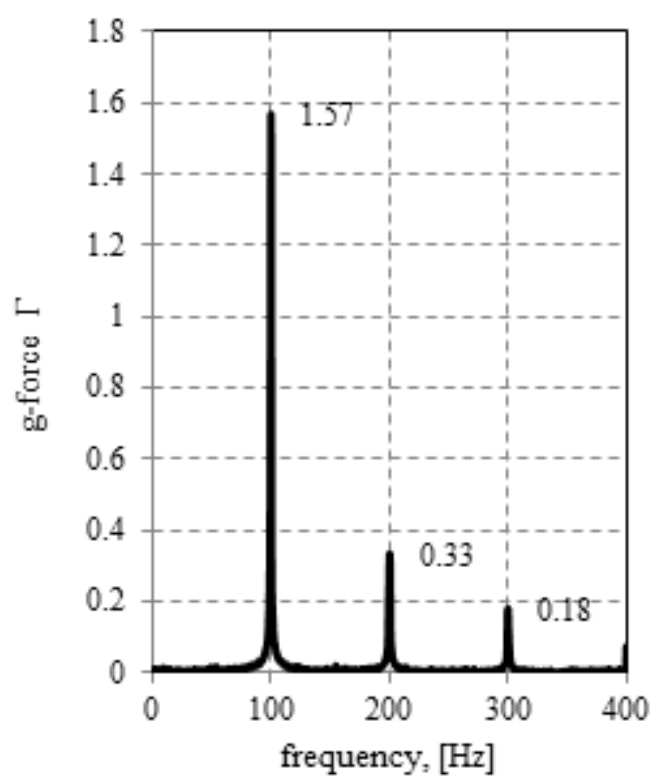

(b)

Figure 10. Characteristics of overloads of the body mass of the vibro-impact $100 \mathrm{~Hz}$ system when $U_{0}=250 \mathrm{~V}:$ a) - oscillogram, b) spectral analysis

The next important stage of the investigation was the implementation of the vibro-impact system of the improved efficiency. In order to do this, the spring with the reduced stiffness for the value of the parameter $\Theta=0.8$ was made. The investigation was carried out for the value of the coefficient $\Lambda=2.2$ (see Fig. 11). The results presented in Table 2 indicate the significant power advantages of the vibro-impact systems calculated using the new technique. 


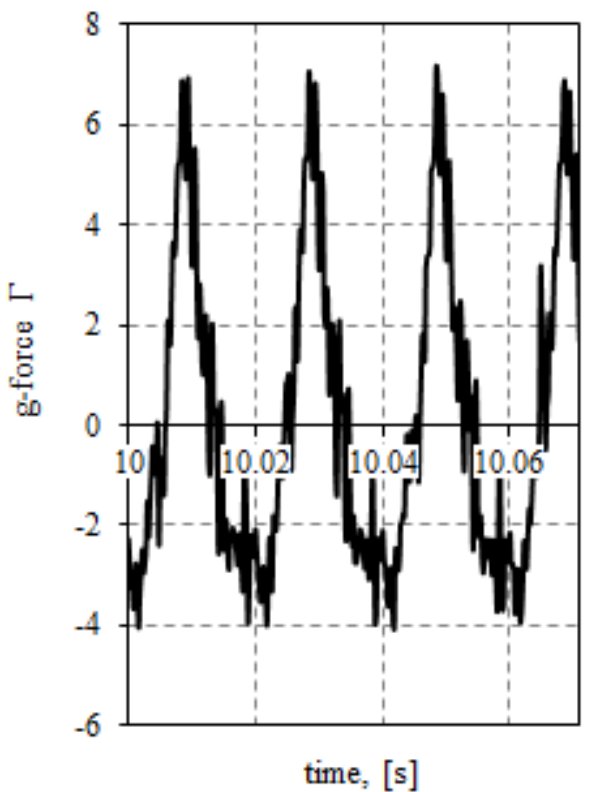

(a)

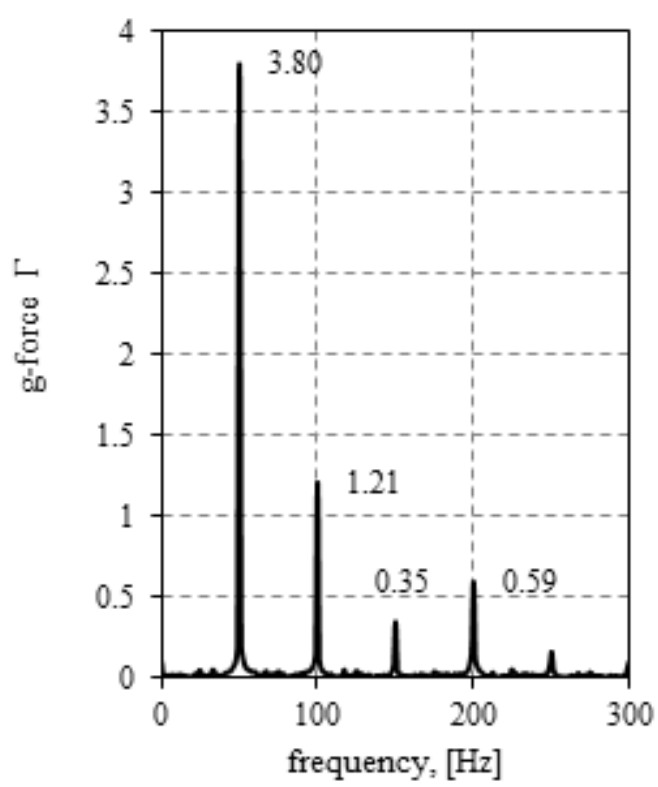

(b)

Figure 11. Kinematic characteristics of the new vibro-impact system when $U_{0}=110 \mathrm{~V}:$ a) - oscillogram of overloads; b) - spectrums of overloads of the body mass

Table 2. Results of the experimental investigations of the resonant vibratory device

\begin{tabular}{|c|c|c|c|c|c|c|c|}
\hline System & $\mathrm{f},[\mathrm{Hz}]$ & $\mathrm{f}_{0},[\mathrm{~Hz}]$ & $\Gamma$ & $\mathrm{k}_{\mathrm{a}}$ & $\mathrm{U}_{0},[\mathrm{~V}]$ & $\mathrm{I}_{0},[\mathrm{~A}]$ & $\varsigma_{\mathrm{a}},\left[\left(\mathrm{m} / \mathrm{s}^{2}\right) / \mathrm{VA}\right]$ \\
\hline \multirow{3}{*}{ single-frequency } & 50 & 53.5 & 9.2 & 1.25 & 165 & 3.2 & 0.17 \\
\cline { 2 - 8 } & 100 & 105.6 & 10.7 & 1.34 & 205 & 2.4 & 0.21 \\
\hline \multirow{3}{*}{ vibro-impact } & 50 & $72.4^{*}$ & 10 & 2.3 & 220 & 3 & 0.15 \\
\cline { 2 - 8 } & $\mathbf{5 0}$ & $\mathbf{5 7 . 9 *}$ & $\mathbf{7 . 2}$ & $\mathbf{2}$ & $\mathbf{1 1 0}$ & $\mathbf{1 . 5}$ & $\mathbf{0 . 4 3}$ \\
\cline { 2 - 8 } & 100 & $144.7^{*}$ & 3.2 & 2 & 250 & 2.8 & 0.05 \\
\hline
\end{tabular}

* - calculated value; italic and bold - system with higher efficiency

\section{Conclusions}

Due to the system approach and the complex problems, we ascertained:

- The expediency of use of multi-criteria evaluation of the quality of operation of vibratory machines of various types taking into account two partial technological parameters and two power indexes while developing and choosing the type of the machine for the certain technological process.

- Asymmetric elastic characteristic with the highly efficient vibro-impact mode considering the maximal value of the acceleration of the working mass.

- Qualitative conditions for ensuring the vibro-impact resonant modes on the basis of optimization problems with restraints on kinematic parameters (acceleration) and dynamic characteristics (natural frequency of oscillations). In this case, the proposed approach is of the generalized character and may be adapted for machines of various technological purposes.
- The possibilities of implementation and experimental evaluation of single-frequency and vibro-impact modes with the excitation frequencies of $50 \mathrm{~Hz}$ and $100 \mathrm{~Hz}$. In this case, the scheme of implementation of vibro-impact modes of improved efficiency (more than 2 times higher efficiency) using one flat spring with intermediary cylindrical supports has been confirmed.

Therefore, the developed complex means for evaluation, synthesis, optimization of parameters of multi-frequency resonant machines have a high practical value, which is confirmed by the corresponding theoretical results during the modelling (simulation) and partly in practice.

\section{REFERENCES}

[1] Michalczyk, J. Maszyny wibracyjne. Obliczenia dynamiczne, drgania, hałas. WNT, Warszawa, 1995.

[2] Awrejcewicz, Jan. Vibro-impact dynamics control in the 
resonance case. Computation Mechanics: conference paper, (1998), 1-16.

[3] Olejnik, P. Metody numeryczne rozwiązywania, analizy i kontroli nieciągłych układów dynamicznych. Zeszyty Naukowe. Rozprawy Naukowe, Politechnika Łódzka 444, 2013.

[4] Yevstignejev, V. Application of the complete bifurcation groups method for analysis of strongly nonlinear oscillators and vibro-impact systems. Ph.D. thesis, Riga Technical University, Riga, Latvia, 2008.

[5] Gursky, V., and Kuzio, I. Strength and durability analysis of a flat spring at vibro-impact loadings. Eastern-European Journal of Enterprise Technologies 5, 7 (83) (2016), 4-10.

[6] Despotovic, Z., and Urukalo, D., and Lecic, M., and Cosic, A. Mathematical modeling of resonant linear vibratory conveyor with electromagnetic excitation: simulations and experimental results. Applied Mathematical Modelling. 41, (2017), 1-24.

[7] Sokolov, I., and Babitsky, V., and Halliwell, N. Autoresonant vibro-impact system with electromagnetic excitation. Journal of Sound and Vibration 308, (2007), 375-391. 